\title{
New Polyimides Incorporated with Diphenylpyrenylamine Unit as Fluorophore and Redox-Chromophore
}

\author{
YI-CHUN KUNG, ${ }^{1}$ WEN-FU LEE, ${ }^{1}$ SHENG-HUEI HSIAO, ${ }^{2}$ GUEY-SHENG LIOU ${ }^{3}$ \\ ${ }^{1}$ Department of Chemical Engineering, Tatung University, Taipei, Taiwan \\ ${ }^{2}$ Department of Chemical Engineering and Biotechnology, National Taipei University of Technology, Taipei, Taiwan \\ ${ }^{3}$ Institute of Polymer Science and Engineering, National Taiwan University, Taipei, Taiwan
}

Received 27 January 2011; accepted 26 February 2011

DOI: $10.1002 /$ pola.24652

Published online 24 March 2011 in Wiley Online Library (wileyonlinelibrary.com).

\begin{abstract}
A series of novel polyimides based on N,N-di(4-aminophenyl)-1-aminopyrene and aromatic or alicyclic tetracarboxylic dianhydrides were synthesized. The polymers exhibited good solubility in many polar organic solvents and could afford robust films via solution casting. The polyimides derived from aromatic dianhydrides exhibited high thermal stability and high glass-transition temperatures $\left(333-364^{\circ} \mathrm{C}\right)$. Cyclic voltammetry studies of the polymer films showed that these polyimides are both $\mathrm{p}$ and $\mathrm{n}$ dopable and have multicolored
\end{abstract}

electrochromic states. For the polyimides derived from alicyclic dianhydrides, they revealed a strong blue-light emission with high fluorescence quantum yields $\left(\Phi_{\mathrm{PL}}>45 \%\right)$ and a marked solvatochromic behavior. (c) 2011 Wiley Periodicals, Inc. J Polym Sci Part A: Polym Chem 49: 2210-2221, 2011

KEYWORDS: cyclic voltammetry; electrochemistry; electrochromic polymers; polyimides; pyrenylamine; redox polymers; spectroelectrochemistry
INTRODUCTION Aromatic polyimides are characterized as highly thermally stable polymers with a favorable balance of physical and chemical properties. They are commercially important materials used extensively as dielectric films and coatings in a wide range of high technology applications. ${ }^{1}$ However, rigidity of the backbone and strong interchain interactions result in high melting or glass-transition temperatures $\left(T_{\mathrm{g}}\right)$ and limited solubility in most organic solvents. Thus, polyimide processing is generally carried out via poly(amic acid) precursor and then converted to polyimide by vigorous thermal or chemical cyclodehydration. This process has inherent problems such as emission of volatile by-products and storage instability of poly(amic acid) solution. To overcome these problems, many attempts have been made to the synthesis of soluble and processable polyimides in fully imidized form while maintaining their excellent properties. ${ }^{2}$ The majority of methods used for improving the solubility while maintaining the high-temperature performance of polyimides have involved the structural modifications of dianhydride and diamine monomers. Typical approaches include the introduction of flexible linkages, kinked or unsymmetrical structures, bulky packing-disruptive units, and bulky lateral groups into the polymer backbone. ${ }^{3}$

Pyrene is a flat aromatic molecule with four fused benzene rings. Among the attractive properties of pyrene is its ready functionalization, appearance of delayed fluorescence, distinct solvatochromic phenomena, and its high propensity for forming excimers. ${ }^{4}$ Pyrene and its derivatives have been extensively studied for application as fluorescence probes in many applications. ${ }^{5}$ In recent years, pyrene derivatives, ${ }^{6}$ polymers, ${ }^{7}$ starbursts, ${ }^{8}$ and dendrimers ${ }^{9}$ have been reported in the context of organic electronic applications such as organic light-emitting devices (OLEDs), due to their emissive properties combined with high charge carrier mobility. Although pyrene is a blue-emitting chromophore, the use of pyrene as emitting materials in OLED applications has been limited due to aggregation between planar pyrene molecules. The high tendency toward $\pi$-stacking of the pyrene moieties generally lends the pyrene-containing emitters strong intermolecular interactions in the solid state, which leads to a substantial red shift of their fluorescence emission and a decrease of the fluorescence quantum yields. Fortunately, through molecular structure design, the close packing/fluorescence quenching effect in pyrene-type materials can be reduced or controlled. For example, a successful effort in the prevention of $\pi$-stacking in small molecules was achieved with 1,3,6,8-tetrasubstituted highly sterically hindered pyrenes $^{10}$ that can emit blue light in solution as well as in the solid state with a high-efficient yield. Additionally, diarylamino-functionalized pyrene derivatives have been found to perform efficiently as emitters and charge transport materials in OLEDs. ${ }^{11}$

Triarylamines are an important class of compounds because they form stable aminium radical cations. Thus, triarylamines 
can be building blocks for high-spin polyradicals that showed ferromagnetic coupling. ${ }^{12}$ Perhaps most commonly, triarylamines have been used as the hole-transport layer in electroluminescent devices, ${ }^{13,14}$ because the two-layered organic electroluminescent device using a diamine as a hole-transfer layer was first reported by Tang and VanSlyke in $1987 .{ }^{15}$ Triarylamines can be easily oxidized to form stable radical cations, and the oxidation process is always associated with a noticeable change of coloration. In recent years, we have developed a number of polyimides ${ }^{16}$ and polyamides ${ }^{17}$ carrying the triarylamine unit as a redox-chromophore. The triarylamine-containing monomers such as diamines and dicarboxylic acids could be easily prepared using a wellestablished procedure, and they could react with the corresponding comonomers through conventional polycondensation techniques, producing the desired triarylamine-based polymers. The polymers have high glass-transition and decomposition temperature. Because of the incorporation of packing-disruptive, propeller-shaped triarylamine units along the polymer backbone, most of these polymers exhibited good solubility in polar organic solvents. They could afford tough and flexible films with good mechanical properties via simple solution processing methods. This is advantageous for their ready fabrication of large-area, thin-film devices. Thus, incorporation of three-dimensional, packing-disruptive triarylamine units into the polyimide backbone not only resulted in enhanced solubility but also led to new electronic functions of polyimides such as electrochromic characteristics.

In view of the attractive properties associated with the pyrene and triarylamine units, we have recently reported the synthesis and electrochemical and optical behaviors of diphenylpyrenylamine-containing polyamides. ${ }^{18}$ It was found that the polyamides display reversible oxidation and reduction processes, indicating their high electrochemical stability for both $\mathrm{p}$ and $\mathrm{n}$-doping of the diphenylpyrenylamine core. These polyamides also showed interesting fluorescent and electrochromic characteristics. Very recently, we have demonstrated that the incorporation of diphenylpyrenylamine units into the polyimide backbone leads to solubility-enhanced, high- $T_{\mathrm{g}}$, and ambipolar and multi-electrochromic polyimide electrochromics. ${ }^{19}$ This encouraging result drove us to explore more about these materials. In this work, we report the synthesis and characterization of a series of novel polyimides based on $\mathrm{N}, \mathrm{N}$-di(4-aminophenyl)-1-aminopyrene and various aromatic or alicyclic tetracarboxylic dianhydrides. In addition to the basic and electrochromic characterization, photoluminescent properties of the resulted polyimides are also studied and compared with those of structurally related ones from 4,4'-diaminotriphenylamine.

\section{EXPERIMENTAL}

\section{Materials}

According to a literature procedure, ${ }^{20}$ the pyrenylamine-containing diamine monomer $\mathrm{N}, \mathrm{N}$-di(4-aminophenyl)1-aminopyrene (1) was synthesized by the cesium fluoride-mediated $\mathrm{C}-\mathrm{N}$ coupling reaction of 1-aminopyrene with $p$-fluoronitrobenzene, followed by hydrazine Pd/C-catalytic reduction. The
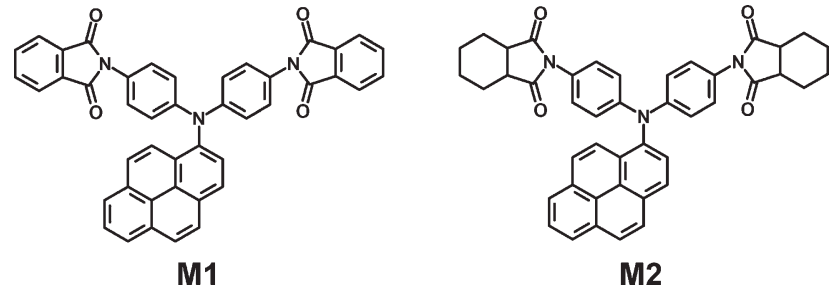

synthetic details and the characterization data of this diamine monomer have been reported previously. ${ }^{18}$ Synthesis and characterization data (Supporting Information Figs. S1S5) of model compounds $\mathrm{N}, \mathrm{N}$-di(phthalimido)-1-aminopyrene (M1) and $N, N$-di(1,2-cyclohexanedicarboximido)-1-aminopyrene (M2) are included in the Supporting Information. $N, N$ Dimethylacetamide (DMAc) (Tedia), $N, N$-dimethylformamide (DMF) (Tedia), pyridine (Py) (Wako), and $N$-methyl-2-pyrrolidone (NMP) (Tedia) were dried over calcium hydride for 24 h, distilled under reduced pressure, and stored over $4 \AA$ molecular sieves in a sealed bottle. Pyromellitic dianhydride (PMDA; 2a, from Aldrich), 3,3',4,4'-benzophenonetetracarboxylic dianhydride (BTDA; 2c, from Aldrich), and 1,2,3,4-cyclopentanetetracarboxylic dianhydride (CPDA; 2g, form TCI) were recrystallized from acetic anhydride and then vacuum dried. 3,3',4,4'-Biphenyltetracarboxylic dianhydride (BPDA; 2b, from Oxychem), 4,4'-oxydiphthalic anhydride (ODPA; 2d, from Oxychem), 3,3',4,4'-diphenylsulfonetetracarboxylic dianhydride (DSDA; 2e, from New Japan Chemical), 2,2-bis(3,4dicarboxyphenyl)hexafluoropropane dianhydride (6FDA; 2f, from Hoechst Celanese), and bicycle[2,2,2]oct-7-ene-2,3,5,6tetracarboxylic dianhydride (BODA; $2 \mathbf{h}$, from Acros) were heated at $250{ }^{\circ} \mathrm{C}$ in vacuo for $3 \mathrm{~h}$ before use. Tetrabutylammonium perchlorate $\left(\mathrm{Bu}_{4} \mathrm{NClO}_{4}\right)$ (TCI) was recrystallized twice from ethyl acetate under nitrogen atmosphere and then dried in vacuo before use. All other reagents were used as received from commercial sources.

\section{Synthesis of Polyimides}

A typical procedure is as follows. The diamine monomer $\mathbf{1}$ (0.473 g, $1.18 \mathrm{mmol}$ ) was dissolved in $9.5 \mathrm{~mL}$ of anhydrous DMAc in a $50-\mathrm{mL}$ round-bottom flask. Then dianhydride $\mathbf{2 f}$, 6FDA (0.527 g, $1.18 \mathrm{mmol})$ was added to the diamine solution in one portion. Thus, the solid content of the solution is approximately $10 \mathrm{wt} \%$. The mixture was stirred at room temperature for about $12 \mathrm{~h}$ to yield a viscous poly(amic acid) solution. The inherent viscosity of the resulting poly(amic acid) was $1.49 \mathrm{dL} \mathrm{g}^{-1}$, measured in DMAc at a concentration of $0.5 \mathrm{~g} \mathrm{dL}^{-1}$ at $30{ }^{\circ} \mathrm{C}$. The poly(amic acid) film was obtained by casting from the reaction polymer solution onto a glass Petri-dish and drying at $90{ }^{\circ} \mathrm{C}$ overnight. The poly(amic acid) in the form of solid film was converted to polyimide $\mathbf{3 f}$ by successive heating under vacuum at $150{ }^{\circ} \mathrm{C}$ for $30 \mathrm{~min}, 200{ }^{\circ} \mathrm{C}$ for $30 \mathrm{~min}$, and then $250{ }^{\circ} \mathrm{C}$ for $1 \mathrm{~h}$. The inherent viscosity of polyimide $3 \mathbf{f}$ was $0.52 \mathrm{dL} \mathrm{g}^{-1}$, measured at a concentration of $0.5 \mathrm{~g} \mathrm{dL}^{-1}$ in DMAc at $30{ }^{\circ} \mathrm{C}$. The IR spectrum of $\mathbf{3 f}$ (Supporting Information Fig. S6) exhibited characteristic imide absorption bands at $1786 \mathrm{~cm}^{-1}$ 
(asymetrical $\mathrm{C}=0$ stretch) and $1722 \mathrm{~cm}^{-1}$ (symmetrical $\mathrm{C}=0$ stretch).

${ }^{1} \mathrm{H}$ NMR (500 $\mathrm{MHz}, \mathrm{CDCl}_{3}, \delta$, ppm) (for the peak assignments, see Supporting Information Fig. S7): 7.22-7.27 (two overlapped AB doublets, $\left.8 \mathrm{H}, \mathrm{H}_{\mathrm{j}}+\mathrm{H}_{\mathrm{k}}\right), 7.83\left(\mathrm{~d}, 2 \mathrm{H}, \mathrm{H}_{\mathrm{n}}\right), 7.90$ $\left(\mathrm{d}, 1 \mathrm{H}, \mathrm{H}_{\mathrm{a}}\right), 7.91\left(\mathrm{~s}, 2 \mathrm{H}, \mathrm{H}_{\mathrm{l}}\right), 7.99-8.03\left(\mathrm{~m}, 4 \mathrm{H}, \mathrm{H}_{\mathrm{m}}+\mathrm{H}_{\mathrm{f}}+\right.$ $\left.\mathrm{H}_{\mathrm{d}}\right)$, 8.06-8.11 (m, $\left.2 \mathrm{H}, \mathrm{H}_{\mathrm{i}}+\mathrm{H}_{\mathrm{h}}\right), 8.14-8.17\left(\mathrm{~m}, 2 \mathrm{H}, \mathrm{H}_{\mathrm{c}}+\mathrm{H}_{\mathrm{e}}\right)$, 8.19-8.22 (t, 2H, $\left.\mathrm{H}_{\mathrm{g}}+\mathrm{H}_{\mathrm{b}}\right)$.

For the chemical imidization method, $4 \mathrm{~mL}$ of acetic anhydride and $2 \mathrm{~mL}$ of Py were added to the poly(amic acid) solution obtained by a similar process as above, and the mixture was heated at $100{ }^{\circ} \mathrm{C}$ for $1 \mathrm{~h}$ to effect a complete imidization. The homogenous polymer solution was poured slowly into $200 \mathrm{~mL}$ of stirring methanol giving rise to yellow precipitate that was collected by filtration, washed thoroughly with hot water and methanol, and dried. A polymer solution was made by the dissolution of about $0.5 \mathrm{~g}$ of the polyimide sample in $10 \mathrm{~mL}$ of hot DMAc. The homogeneous solution was poured into a 9-cm glass Petri dish, which was placed in a $90{ }^{\circ} \mathrm{C}$ oven overnight for the slow release of the solvent, and then the film was stripped off from the glass substrate and further dried in vacuum at $160{ }^{\circ} \mathrm{C}$ for $6 \mathrm{~h}$.

\section{Measurements}

Infrared spectra were recorded on a Horiba FT-720 FTIR spectrometer, and the ${ }^{1} \mathrm{H}$ and ${ }^{13} \mathrm{C}$ NMR spectra on a 500 $\mathrm{MHz}$ instrument (Bruker AVANCE-500 FT-NMR system) using DMSO- $d_{6}$ as the solvent and tetramethylsilane as the internal standard. Elemental analyses were run in a Heraeus VarioELIII CHNS elemental analyzer. The inherent viscosities of the polymers were determined at $0.5 \mathrm{~g} \mathrm{dL}^{-1}$ concentration using an Ubbelohde viscometer at $30{ }^{\circ} \mathrm{C}$. Weight-average molecular weights $\left(M_{\mathrm{w}}\right)$ and number-average molecular weights $\left(M_{\mathrm{n}}\right)$ were obtained via gel permeation chromatography (GPC) based on polystyrene calibration using Waters 2410 as an apparatus and THF as the eluent. Wide-angle X-ray diffraction (WAXD) measurements were performed at room temperature (ca. $25^{\circ} \mathrm{C}$ ) on a Shimadzu XRD-6000 X-ray diffractometer $(40 \mathrm{kV}, 20 \mathrm{~mA})$, using graphite-monochromatized $\mathrm{Cu}-\mathrm{K} \alpha$ radiation. Thermogravimetric analyses (TGA) were conducted with a PerkinElmer Pyris 1 TGA, at a heating rate of $20{ }^{\circ} \mathrm{C} \mathrm{min}^{-1}$ in flowing nitrogen or air (flow rate $=20$ $\mathrm{cm}^{3} \min ^{-1}$ ). DSC analyses were performed on a PerkinElmer Pyris 1 differential scanning calorimeter at a scan rate of 20 ${ }^{\circ} \mathrm{C} \min ^{-1}$ under nitrogen. Ultraviolet-visible (UV-vis) spectra of the polymer films were recorded on an Agilent 8453 UVvisible spectrometer. Photoluminescence (PL) spectra were measured with a Varian Cary Eclipse fluorescence spectrophotometer. Solution fluorescence quantum yields $\left(\Phi_{\mathrm{PL}}\right)$ of the samples in NMP were determined by using the method of Demas and Crosby $^{21}$ with 9,10-diphenylanthracene in cyclohexane $\left(1 \times 10^{-5} \mathrm{M}\right)$ as a reference $\left(\Phi_{\mathrm{PL}}=90 \%\right)$. Cyclic voltammetry (CV) measurements were carried out using a $\mathrm{CH}$ instruments model $600 \mathrm{C}$ potentiostat. Conventional three electrodes assembly was used under nitrogen to record cyclic voltammograms. The working electrode was an ITO-coated glass electrode. The counter-electrode was a plat- inum wire, and $\mathrm{Ag} / \mathrm{AgCl}$ was used as the reference electrode. The scan rate was $100 \mathrm{mV} \mathrm{s}^{-1}$. The $0.1 \mathrm{M}$ tetrabutylammonium perchlorate $\left(\mathrm{Bu}_{4} \mathrm{NClO}_{4}\right)$ in anhydrous acetonitrile $\left(\mathrm{CH}_{3} \mathrm{CN}\right)$ or DMF was used as a supporting electrolyte. Ferrocene was used as an external reference for calibration $(+0.48 \mathrm{~V}$ vs. $\mathrm{Ag} / \mathrm{AgCl})$. For the spectroelectrochemical experiments, the polymer film was cast on an ITO-coated glass slide (a piece that fit in the commercial UV-visible cuvette), and a homemade electrochemical cell was built from a commercial UV-visible cuvette. The cell was placed in the optical path of the sample light beam in an Agilent 8453 UV-visible diode array spectrophotometer. The electronic absorption spectra of the polymer film on the ITO-glass were recorded under potential control in a $0.1 \mathrm{M} \mathrm{Bu}_{4} \mathrm{NClO}_{4} /$ $\mathrm{CH}_{3} \mathrm{CN}$ or DMF solution.

\section{RESULTS AND DISCUSSION}

\section{Synthesis and Basic Characterization of Polyimides}

A series of novel polyimides $\mathbf{3 a} \mathbf{a} \mathbf{3} \mathbf{h}$ with main-chain diphenylpyrenylamine units were prepared in conventional twostep method by the reactions of equal molar amounts of diamine 1 with various aromatic or alicyclic dianhydrides (2a$\mathbf{2 h}$ ) to form poly(amic acid)s, followed by the thermal or chemical cyclodehydration (Scheme 1). As shown in Supporting Information Table S1, the inherent viscosities of the poly(amic acid) precursors derived from aromatic dianhydrides 2a-2f were in the range 1.46-2.02 $\mathrm{dL} \mathrm{g}^{-1}$. The molecular weights of these poly(amic acid)s were sufficiently high to permit the casting of flexible and tough poly(amic acid) films, which were subsequently converted into tough polyimide films by stage-by-stage heating to elevated temperatures. The transformation from poly(amic acid) to a polyimide could also be carried out via chemical cyclodehydration by using acetic anhydride and Py. Polyimides $\mathbf{3 d - 3 f}$ were soluble in polar solvents such as NMP and DMAc. Therefore, the characterization of solution viscosity was carried out without any difficulty. The inherent viscosities of polyimides $\mathbf{3 d - f}$ were recorded in the range of $0.48-0.66 \mathrm{dL} \mathrm{g}^{-1}$, as measured in DMAc at $30{ }^{\circ} \mathrm{C}$. The 6FDA-derived polyimide $\mathbf{3 f}$ was also soluble in less polar THF. The GPC measurement of this polyimide using THF as the eluent showed weight-average molecular weight $\left(M_{\mathrm{w}}\right)$ of 75,000 and polydispersity index $\left(M_{\mathrm{w}} / M_{\mathrm{n}}\right)$ of 1.53, relative to polystyrene standards. Less favorable results were obtained from the reactions of diamine $\mathbf{1}$ with alicyclic dianhydrides such as CPDA (2g) and BODA (2h). The poly(amic acid) precursors of polyimides $\mathbf{3 g}$ and $\mathbf{3 h}$ were produced with a relatively lower inherent viscosity of 0.19 and $0.21 \mathrm{dL} \mathrm{g}^{-1}$, respectively, and they could not afford flexible films upon solution casting. However, adherent solid films could be cast on the glass substrate from the NMP or DMAc solutions of polyimides $\mathbf{3 g}$ and $\mathbf{3 h}$. Structural features of these polyimides were characterized by IR and NMR analysis. A typical set of IR spectra for polyimide $\mathbf{3 f}$ and its poly(amic acid) precursor are presented in the Supporting Information Figure S6. All polyimides exhibited characteristic imide group absorptions around 1785 and $1720 \mathrm{~cm}^{-1}$ (typical of imide carbonyl asymmetrical and symmetrical stretch), $1380 \mathrm{~cm}^{-1}(\mathrm{C}-\mathrm{N}$ 

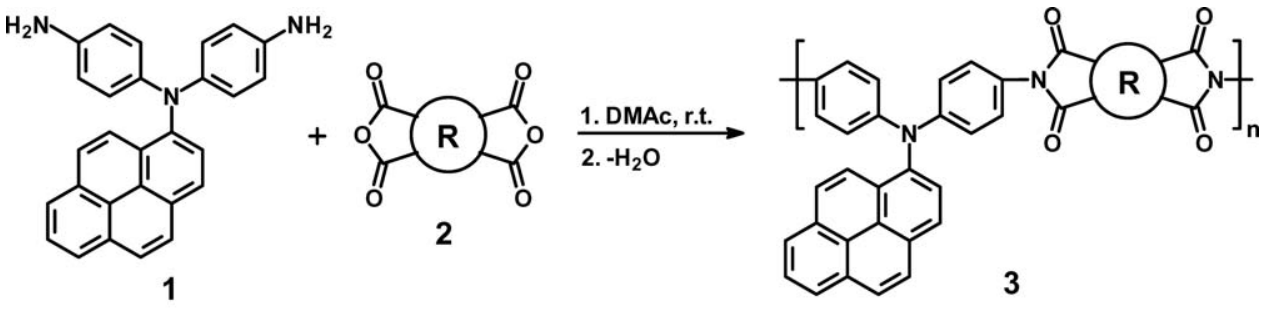

$\mathbf{R}=$

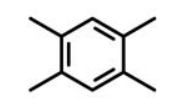

a

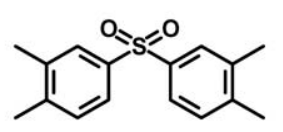

e

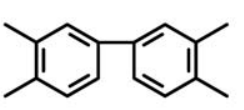

b

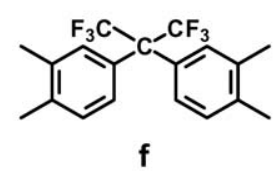

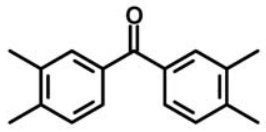

c

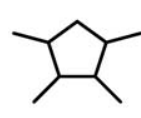

g

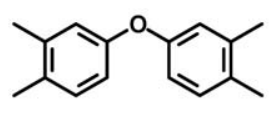

d

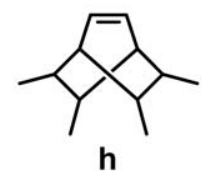

amine-based polyimides.

stretch), and 1100 and $720 \mathrm{~cm}^{-1}$ (imide ring deformation). The disappearance of amide and carboxyl bands indicates a virtually complete conversion of the poly(amic acid) precursor into polyimide. Representative ${ }^{1} \mathrm{H}$ NMR and $\mathrm{H}-\mathrm{H}$ COSY NMR spectra of polyimide 3f in DMSO- $d_{6}$ are illustrated in Supporting Information Figure S7, and the resonance peaks are well assigned to the repeat structure of the polymer backbone. In addition, the elemental analysis values were in good agreement with the calculated ones of the proposed structures of these polyimides.

The solubility properties of polyimides $\mathbf{3 a}-\mathbf{3 h}$ in some selected organic solvents at $10 \%(\mathrm{w} / \mathrm{v})$ are also displayed in Supporting Information Table S1. As mentioned above, the polyimides (3d-f) derived from less stiff dianhydride components exhibited good solubility in dipolar solvents such as NMP, DMAc, DMF, and DMSO. Polyimide $\mathbf{3 f}$ also showed good solubility in less polar solvents like THF because of the additional contribution of the hexafluoroisopropylidene $\left(-\mathrm{C}\left(\mathrm{CF}_{3}\right)_{2}-\right)$ fragment in the polymer backbone. In general, these polymers revealed an enhanced solubility with respect to conventional aromatic polyimides and their triphenylamine-based analogs (the $\mathbf{3}^{\prime}$ series polymers as shown in the footnotes of Table S1 in Supporting Information). Therefore, the good solubility makes these polymers potential candidates for practical applications in spin-coating and inkjet-printing techniques to afford high performance thin films for optoelectronic devices. The WAXD patterns of the film samples indicated that all the $\mathbf{3}$ series polyimides were essentially amorphous (Supporting Information Fig. S8). Their good solubility and amorphous properties can be attributed in part to the incorporation of bulky, three-dimensional diphenylpyrenylamine moiety along the polymer backbone, which results in a high steric hindrance for close packing, and thus reduces their crystallization tendency and interchain interactions.

\section{Thermal Properties}

The thermal stability and phase-transition temperatures of these polyimides were recorded by thermogravimetric analy- sis (TGA) and differential scanning calorimetry (DSC). The thermal behavior data of are summarized in Table 1. A typical set of TGA and DSC curves of polyimide $\mathbf{3 b}$ are illustrated in Figure 1. Except for the aliphatic-aromatic polyimides $\mathbf{3 g}$ and $\mathbf{3 h}$, these polyimides did not show significant weight loss before $500{ }^{\circ} \mathrm{C}$ in air or nitrogen atmosphere. The

TABLE 1 Thermal Properties of Polyimides ${ }^{a}$

\begin{tabular}{|c|c|c|c|c|}
\hline \multirow{2}{*}{$\begin{array}{l}\text { Polymer } \\
\text { Code }\end{array}$} & \multirow[b]{2}{*}{$T_{\mathrm{g}}\left({ }^{\circ} \mathrm{C}\right)^{\mathrm{b}}$} & \multicolumn{2}{|c|}{$\begin{array}{c}T_{\mathrm{d}} \text { at } 10 \mathrm{wt} \% \\
\text { Loss }\left({ }^{\circ} \mathrm{C}\right)^{\mathrm{c}}\end{array}$} & \multirow{2}{*}{$\begin{array}{l}\text { Char } \\
\text { Yield }(\%)^{d}\end{array}$} \\
\hline & & $\ln \mathrm{N}_{2}$ & In Air & \\
\hline $3 a$ & $364(-)^{\mathrm{e}}$ & $626(606)^{\mathrm{e}}$ & $600(596)^{\mathrm{e}}$ & 68.7 \\
\hline $3 \mathbf{b}$ & 364 (331) & $631(613)$ & 614 (619) & 77.7 \\
\hline $3 c$ & 349 (309) & $609(590)$ & $607(590)$ & 72.0 \\
\hline 3d & $333(295)$ & $620(608)$ & $603(611)$ & 73.9 \\
\hline $3 e$ & $346(326)$ & $587(546)$ & $579(577)$ & 69.2 \\
\hline $3 f$ & 349 (316) & $594(581)$ & $577(571)$ & 70.0 \\
\hline $3 g$ & $281(-)$ & $539(-)$ & $494(-)$ & 69.9 \\
\hline $3 \mathrm{~h}$ & $285(-)$ & $5481-$ & $529(-)$ & 70.4 \\
\hline
\end{tabular}

a The polymer film sample were heated at $300{ }^{\circ} \mathrm{C}$ for $1 \mathrm{~h}$ before all the thermal analyses.

${ }^{b}$ The samples were heated from 50 to $400{ }^{\circ} \mathrm{C}$ at a scan rate of $20{ }^{\circ} \mathrm{C}$ min followed by rapid cooling to $50{ }^{\circ} \mathrm{C}$ at $-200{ }^{\circ} \mathrm{C}$ min in nitrogen. The midpoint temperature of baseline shift on the subsequent DSC trace (from 50 to $400{ }^{\circ} \mathrm{C}$ at heating rate $20^{\circ} \mathrm{C} \mathrm{min}$ ) was defined as $T_{\mathrm{g}}$.

${ }^{\mathrm{c}}$ Decomposition temperature at which a $10 \%$ weight loss was recorded by TGA at a heating rate of $20{ }^{\circ} \mathrm{C}$ min.

${ }^{d}$ Residual weight percentages at $800{ }^{\circ} \mathrm{C}$ under nitrogen flow.

e Values shown in parentheses are those of structurally similar polyimides $\mathbf{3}^{\prime}$.

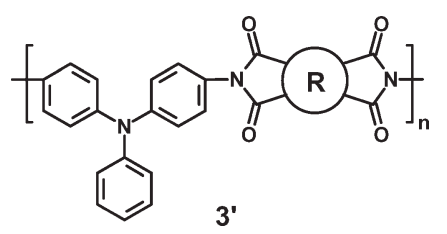




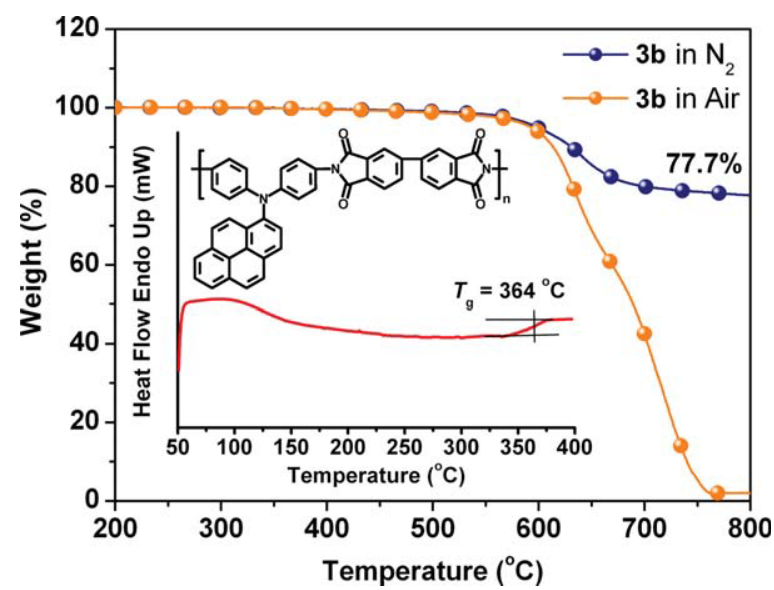

FIGURE 1 DSC and TGA curves of polyimide $\mathbf{3 b}$ with a heating rate at $20{ }^{\circ} \mathrm{C} \mathrm{min}^{-1}$. [Color figure can be viewed in the online issue, which is available at wileyonlinelibrary.com.]

decomposition temperatures $\left(T_{\mathrm{d}}\right)$ at a $10 \%$ weight-loss of the aromatic polyimides ( $3 \mathbf{a}$ to $\mathbf{3 f}$ ) in nitrogen and air were recorded in the range of 587-631 and 577-614 ${ }^{\circ} \mathrm{C}$, respectively. The amount of carbonized residue (char yield) of these polymers was more than $68 \%$ at $800{ }^{\circ} \mathrm{C}$ in nitrogen. The high char yields of these polymers can be ascribed to their high aromatic content. The polyimides $\mathbf{3 g}$ and $\mathbf{3 h}$ in these series exhibited a lower $T_{\mathrm{d}}$ value as compared with 3a-3f obtained from aromatic dianhydrides. This is reasonable when considering the less stable aliphatic segments and low molecular weights. Because of the incorporation of thermally stable pyrene unit, all the polymers exhibited higher $T_{\mathrm{d}}$ values compared to their corresponding $\mathbf{3}^{\prime}$ series counterparts derived from 4,4'-diaminotriphenylamine. These polyimides not only showed good thermal stability but also possessed remarkably high glass-transition temperatures $\left(T_{\mathrm{g}}\right)$ of 281-364 ${ }^{\circ} \mathrm{C}$. The lowest $T_{\mathrm{g}}$ value of $\mathbf{3 g}$ is expected and can be explained in terms of the less stiff cyclopentane segments in its backbone. As compared to the $\mathbf{3}^{\prime}$ series analogs, the present series polyimides exhibit a remarkably increased $T_{\mathrm{g}}$ as a result of the presence of rigid pyrene units. Thus, the thermal analysis results revealed that these polyimides, especially for the aromatic ones, exhibited excellent thermal stability, which in turn is beneficial to increase the service time in device application and enhance the morphological stability to the spin-coated film.

\section{Absorption and Fluorescence}

All the polyimides were examined by UV-vis absorption and PL spectroscopy in both solution and the solid state. The relevant absorption and PL data are collected in Table 2. The absorption and PL profiles of some representative polyimides $\mathbf{3 d}, \mathbf{3 f}, \mathbf{3 g}$, and $\mathbf{3 h}$ in dilute NMP solution are shown in Figure 2. In the absorption spectra, all the polyimides display two prominent bands with unsymmetrical shape and adjoining shoulders. The most bathochromically shifted transitions at about $380 \mathrm{~nm}$ may be ascribed to that originating from the amine to pyrene and amine to imide intramolecular charge-transfer (CT) states. The strong high-energy absorption bands at about $325 \mathrm{~nm}$ are mainly assigned to that arising from pyrene-based $\pi-\pi^{*}$ transitions. Solid state absorption spectra of these polyimides were very similar to those observed in the solution state (Fig. 3), suggesting that the aryl rings do not undergo close $\pi$-stacking. These polyimides in dilute NMP solution emitted deep blue to cyan fluorescence; their emission maxima lie in the region between 419 and $479 \mathrm{~nm}$. The PL quantum yields $\left(\Phi_{\mathrm{PL}}\right)$ of these polyimides in NMP solution were found to vary from 0.20 to $54.3 \%$. The low $\Phi_{\mathrm{PL}}$ of the aromatic polyimides $\mathbf{3 a}-\mathbf{3 f}$ may be attributed to the quenching effect arising from intra- and inter-chain CT complexing between the diphenylpyrenylamine donor and the phthalimide acceptor. It is worth noting that CT-inhibited polyimide $\mathbf{3 g}$ and $\mathbf{3 h}$ derived from alicyclic dianhydrides CPDA (2g) and BODA (2h) had a much higher PL quantum yield of 45.1 and $54.3 \%$. A relatively higher quantum yield of polyimide $3 \mathbf{h}\left(\Phi_{\mathrm{PL}}=54.3 \%\right)$ in

TABLE 2 Photophysical Properties of Polyimides

\begin{tabular}{|c|c|c|c|c|c|c|}
\hline \multirow{2}{*}{$\begin{array}{l}\text { Polymer } \\
\text { Code }\end{array}$} & \multicolumn{3}{|c|}{ In Solution ${ }^{a}$} & \multicolumn{3}{|c|}{ As Solid Film } \\
\hline & $\lambda_{\max }^{\mathrm{Abs}}(\mathrm{nm})$ & $\lambda_{\max }^{\mathrm{PL}}(\mathrm{nm})^{\mathrm{b}}$ & $\Phi_{\mathrm{PL}}(\%)^{\mathrm{c}}$ & $\lambda_{\max }^{\mathrm{Abs}}(\mathrm{nm})$ & $\lambda_{\text {onset }}^{\text {Abs }}(\mathrm{nm})$ & $\lambda_{\max }^{\mathrm{PL}}(\mathrm{nm})$ \\
\hline $3 a$ & 317,361 & 420 & $0.42(0.12)^{d}$ & 319,362 & 464 & $-^{\mathrm{e}}$ \\
\hline $3 b$ & 328,378 & 422 & $0.20(0.11)$ & 328,382 & 468 & - \\
\hline $3 c$ & 315,378 & 421 & $0.28(0.13)$ & 316,382 & 462 & - \\
\hline $3 d$ & 327,380 & 426 & $0.55(0.14)$ & 328,382 & 457 & - \\
\hline $3 e$ & 329,378 & 422 & $0.42(0.11)$ & 330,382 & 460 & - \\
\hline $3 f$ & 328,378 & 419 & $0.82(0.12)$ & 329,382 & 459 & - \\
\hline $3 g$ & 315,379 & 479 & $45.1(6.33)$ & 325,382 & 442 & 486 \\
\hline $3 h$ & 316,380 & 475 & $54.3(-)$ & 321,382 & 440 & 487 \\
\hline
\end{tabular}

a The polymer concentration was $1 \times 10^{-5} \mathrm{~mol} L$ in NMP.

${ }^{b}$ Excited at the absorption maximum for both solution and the solid film states.

${ }^{c}$ Fluorescent quantum yield estimated using 9,10-diphenylanthracene in cyclohexane $\left(1 \times 10^{-5} \mathrm{M}\right)$ as standard $\left(\Phi_{\mathrm{PL}}=90 \%\right)$.
${ }^{d}$ Values in parentheses are data of analogous polyimides $\mathbf{3}^{\prime}$ having the corresponding dianhydride residues (see footnote in Table 1) as in the 3 series.

e Difficult to be defined due to low PL intensity. 


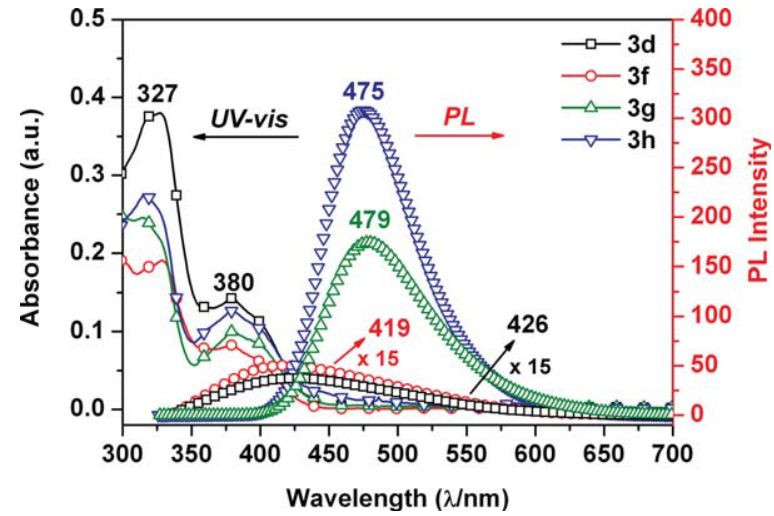

FIGURE 2 UV absorption and PL spectra of dilute NMP solutions (ca. $10^{-5} \mathrm{M}$ ) of polyimides $\mathbf{3 d}, \mathbf{3} \mathbf{f}, \mathbf{3 g}$, and $\mathbf{3 h}$. [Color figure can be viewed in the online issue, which is available at wileyonlinelibrary.com.]

comparison to structurally similar $3 \mathbf{g}\left(\Phi_{\mathrm{PL}}=45.1 \%\right)$ can be rationalized by the fact that the rigid and bulky bicylo[2,2,2] octene group decreased the rotational freedom of the imide linkage and its presence might effectively reduce charge transfer formation within or between polymer chains through steric hindrance and inductive effect (by decreasing the electron-accepting character of dianhydride moieties). Although the quantum yields of polyimides $\mathbf{3 g}$ and $\mathbf{3 h}$ are much higher than those of $\mathbf{3 a - 3} \mathbf{f}$ because of the low CT effect, these numbers are still lower than the small fluorescent pyrene-based molecule. For example, the quantum yield of model compound $\mathbf{M} 2$ measured in NMP is $73.6 \%$. This may be explained by the self-quenching effect due to a little too high density of pyrene functionalities in the polyimide backbone. It is possible to enhance the quantum yield by reducing the molar incorporation ratio of pyrene groups. As shown in Supporting Information Figure S9 and Table S2, a copolyimide (3h-co) prepared from BODA and an equimolar mixture of pyrene-diamine $\mathbf{1}$ and 4,4'-oxydianline revealed

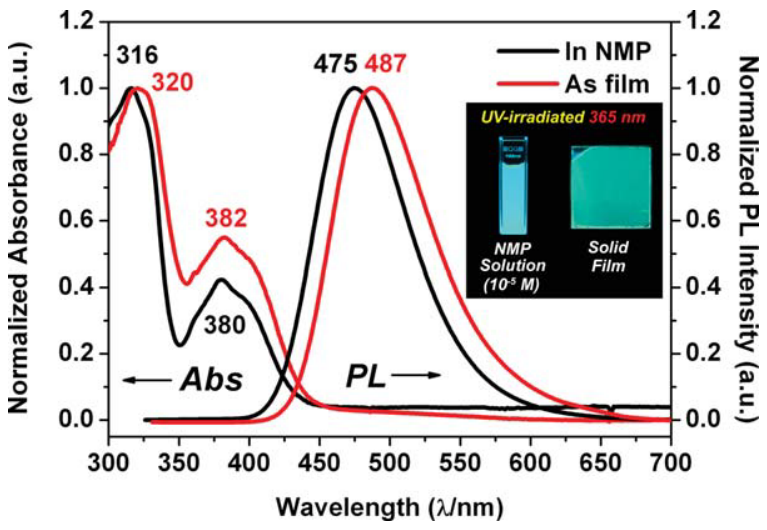

FIGURE 3 Normalized PL spectra of the dilute solution (ca. $10^{-5} \mathrm{M}$ ) and solid film of polyimide $3 \mathrm{~h}$. The inset shows the PL images of the polymer solution and film on exposure to a standard laboratory UV lamp (excited by the $365 \mathrm{~nm}$ light). [Color figure can be viewed in the online issue, which is available at wileyonlinelibrary.com.] an enhanced quantum yield (68.5\%) as compared to the homopolyimide $\mathbf{3 h}$ (45.3\%). The diminished CT interaction of semiaromatic polyimides $\mathbf{3 g}$ and $\mathbf{3 h}$ also reflected in a lighter color of their cast films as compared with the wholly aromatic ones. As shown in Table 2, the thin films of $\mathbf{3 g}$ and 3h had a lower absorption onset wavelength than the other polyimides. When compared with the $\mathbf{3}^{\prime}$ series counterparts, the higher quantum efficiency in the $\mathbf{3}$ series polyimides could be attributable to the presence of rigid, highly fluorescent pyrene chromophore.

\section{Fluorescence Solvatochromism}

It is known that pyrene derivatives exhibited environment sensitive solvatochromic behavior in which the relative intensity of emission bands is dependent on the solvent polarity. $^{22}$ To investigate the solvatochromic properties, we studied the absorption and fluorescence of polyimide $\mathbf{3 h}$ and model compound $\mathbf{M} 2$ in solvents with different polarity. Figure 4 shows the normalized PL spectra of $\mathbf{3 h}$ in dilute solution in various solvents, together with fluorescence images of its solutions. The absorption and PL emission data of $\mathbf{3 h}$ and $\mathbf{M} 2$ are summarized in Table 3. The solution absorption spectra of $\mathbf{3 h}$ are similar, with little shift in the peak maximum (absorption $\lambda_{\max } \sim 320$ and $380 \mathrm{~nm}$ ). This clearly indicates that the solvent polarity exerts little effect on its ground-state electronic transition. In contrast, the PL
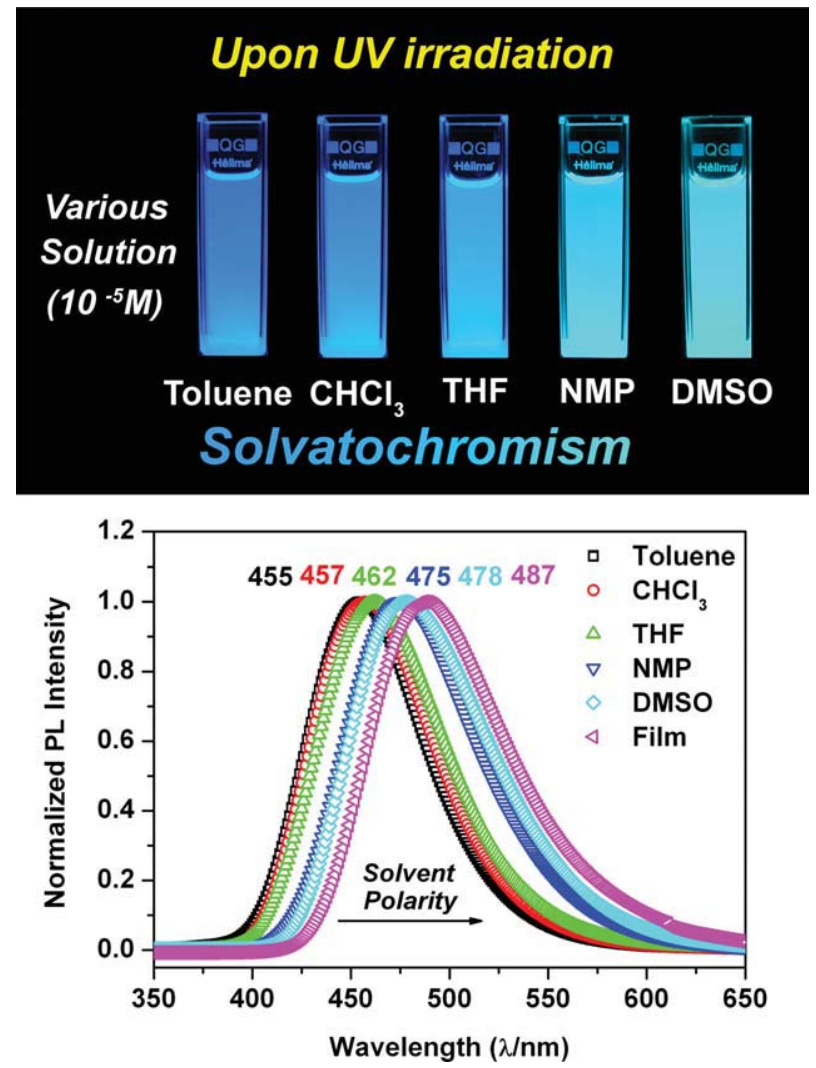

FIGURE 4 Normalized PL spectra of the dilute solutions (ca. $10^{-5} \mathrm{M}$ ) of polyimide $3 \mathrm{~h}$ in different solvents. Photographs show the appearance of the polymer solutions on exposure to a standard laboratory UV lamp (excited by the $365 \mathrm{~nm}$ light). 
TABLE 3 Solvatochromic Properties of Polyimide $\mathbf{3 h}$ in Various Solvents ${ }^{\mathrm{a}}$

\begin{tabular}{|c|c|c|c|c|c|}
\hline Solvents & $\varepsilon^{\mathrm{b}}$ & $\lambda_{\max }^{\mathrm{Abs}}(\mathrm{nm})$ & $\lambda_{\max }^{\mathrm{PL}}(\mathrm{nm})^{\mathrm{c}}$ & $\Phi_{P L}(\%)^{d}$ & FWHM $(n m)^{e}$ \\
\hline Toluene & 2.4 & $322,381(317,382)^{f}$ & $455(442)$ & $65.8(83.2)$ & $70(56)$ \\
\hline $\mathrm{CHCl}_{3}$ & 4.8 & $326,378(318,379)$ & 457 (448) & $62.8(80.6)$ & $73(60)$ \\
\hline THF & 7.5 & $317,380(316,380)$ & 462 (459) & $59.6(77.3)$ & $75(64)$ \\
\hline NMP & 32.2 & $316,380(316,380)$ & 475 (478) & $54.3(73.6)$ & $78(75)$ \\
\hline DMSO & 47.0 & $318,380(318,380)$ & $478(482)$ & $53.6(70.9)$ & $83(77)$ \\
\hline \multicolumn{6}{|c|}{$\begin{array}{l}\text { a Measured at a polymer concentration of about } 10^{-5} \mathrm{M} . \\
\text { b Dielectric constant of the solvent. } \\
{ }^{\mathrm{c}} \text { Excited at the absorption maximum for solution states. } \\
{ }^{\mathrm{d}} \text { The fluorescence quantum yields determined by an integrating sphere, using 9,10-diphenylanthracene as } \\
\text { a standard ( } \Phi_{\mathrm{PL}}=90 \% \text {, measured in dilute cyclohexane solution). } \\
\text { e FWHM = Full-width at half-maximum. } \\
{ }^{f} \text { Values in parentheses are data of model compound } \mathbf{M} 2 .\end{array}$} \\
\hline
\end{tabular}

emission spectra of $\mathbf{3 h}$ show strong solvent-polarity dependence, revealing a dominant broad emission band that undergoes remarkable bathochromic shifts with an increase of the solvent polarity. The emission color changes from deep blue in toluene $\left(\lambda_{\max }=455 \mathrm{~nm}\right)$ to cyan in DMSO $\left(\lambda_{\max }=478\right.$ $\mathrm{nm})$. A decreased fluorescence quantum yield and an increased band width were also observed in the solvent of higher polarity. It is reasonable that the model compound M2 showed a higher PL quantum yield and larger bathochromic shift (442 to $482 \mathrm{~nm}$ ) as compared with polyimide $\mathbf{3 h}$ (Table 3). The solvatochromism could be attributed to the fast intramolecular CT process resulting in a large change of dipole moment in the excited state. Such solvatochromic behavior is associated with the stabilization of the polar emissive excited states by the polar solvents.

\section{Electrochemical Properties}

The electrochemical behavior of each polyimide was investigated by CV using a conventional three-electrode cell assembly. The CV diagrams of the $\mathbf{3 a}-\mathbf{h}$ series polyimides are depicted in Figure 5, and quantitative details are summarized in Table 4. Redox reactions for the pyrenylamine group and some selected diimide systems shown in Scheme 2 represent a possible distribution of electron density for the oxidized or reduced forms and describe by other resonance forms, which contribute to the charge delocalization. Reduction of the imide groups may induce increased quinoid character due to charge separation by the ring structure to minimize the electron-electron repulsion.

All the polyimides underwent a reversible one-electron oxidation and reduction originating from the ambipolar pyrenylamine segment (see Fig. 5 and Scheme 2). The oxidation and reduction peak potentials ( $E_{\mathrm{pa}}$ and $E_{\mathrm{pc}}$ ) of the pyrenylamine units in these polyimides were observed in the range of 1.26 $\sim 1.38 \mathrm{~V}$ and $-1.92 \sim-2.16 \mathrm{~V}$, respectively. As shown in Table 4 , the oxidation onset potentials ( $E_{\text {ox }}^{\text {onset }}$ ) and half-wave potentials $\left(E_{\mathrm{ox}}^{1 / 2}\right)$ were recorded in the range of $0.92-0.97 \mathrm{~V}$ and 1.09-1.13 V, which are slightly lower than those of the corresponding $\mathbf{3}^{\prime}$ counterparts. The decreased oxidation potentials of these polymers should be a result of the incor- poration of the electron-rich pyrene moiety. The polyimides (3a-3f) based on aromatic dianhydrides exhibited additional one, two or three quasi-reversible one-electron reduction peaks due to different aryl imide structures. The CV curve of PMDA polyimide 3a [Fig. 5(a)] shows that the pyromellitimide groups undergo two quasi-reversible one-electron reductions, which occurred at $E_{\mathrm{pc}}=-1.00$ and $-1.48 \mathrm{~V}$. The first reduction corresponds to formation of radical anions, and the second reduction relates to formation of dianions (see Scheme 2). ${ }^{23}$ Similar result was observed with the BPDA polyimide $3 \mathbf{b}$ [Fig. 5(b)]; however, the first reduction process $\left(E_{\mathrm{pc}}=-1.23 \mathrm{~V}\right)$ occurred at a more negative potential than observed for the PMDA polyimide 3a. Two separated reduction peaks peculiar to the BPDA diimide segment indicate a facile electronic communication between the two phthalimide groups. It is worth to note that the benzophenone diimide group of the BTDA polyimide $3 \mathbf{c}$ revealed three reversible redox couples [Fig. 5(c)], similar to those obtained for the conventional BTDA polyimide and diimide model compound. $^{24}$ It was proposed that the first two electroreduction processes occur for the BTDA diimide units, leading to the radical-anion $\left(E_{\mathrm{pc}}=-1.10 \mathrm{~V}\right)$ and diradical-dianion form $\left(E_{\mathrm{pc}}=-1.34 \mathrm{~V}\right)$, respectively. The benzophenone moiety allows a third electroreduction to the proposed radical-trianion form $\left(E_{\mathrm{pc}}=-1.86 \mathrm{~V} ; E_{1 / 2}=-1.75 \mathrm{~V}\right)$ as depicted in Scheme 2. Only one pair of redox waves was observed for the imide reduction of ODPA polyimide $3 \mathbf{d}$ [Fig. 5(d)] and 6FDA polyimide 3f [Fig. 5(f)] during the negative CV scanning, indicating that the conjugation across the imide is interrupted by the ether and hexafluoroisopropylidene bridges. If two phthalimide groups were connected by a nonconjugated bridge, the generated radicals in each part could not be coupled to form a more stable quinoid dianion. With ether or hexafluoroisopropylidene as the connector, reduction of each phthalimide group occurred at nearly the same position. However, the DSDA polyimide $3 \mathbf{e}$ revealed two imide reduction peaks [Fig. 5(e)], even though the conjugation across the imide group is disrupted by the sulfonyl linker. The reason is unkown at this stage and further study is needed. For the polyimides $\mathbf{3 g}$ and $\mathbf{3 h}$ derived from alicyclic 

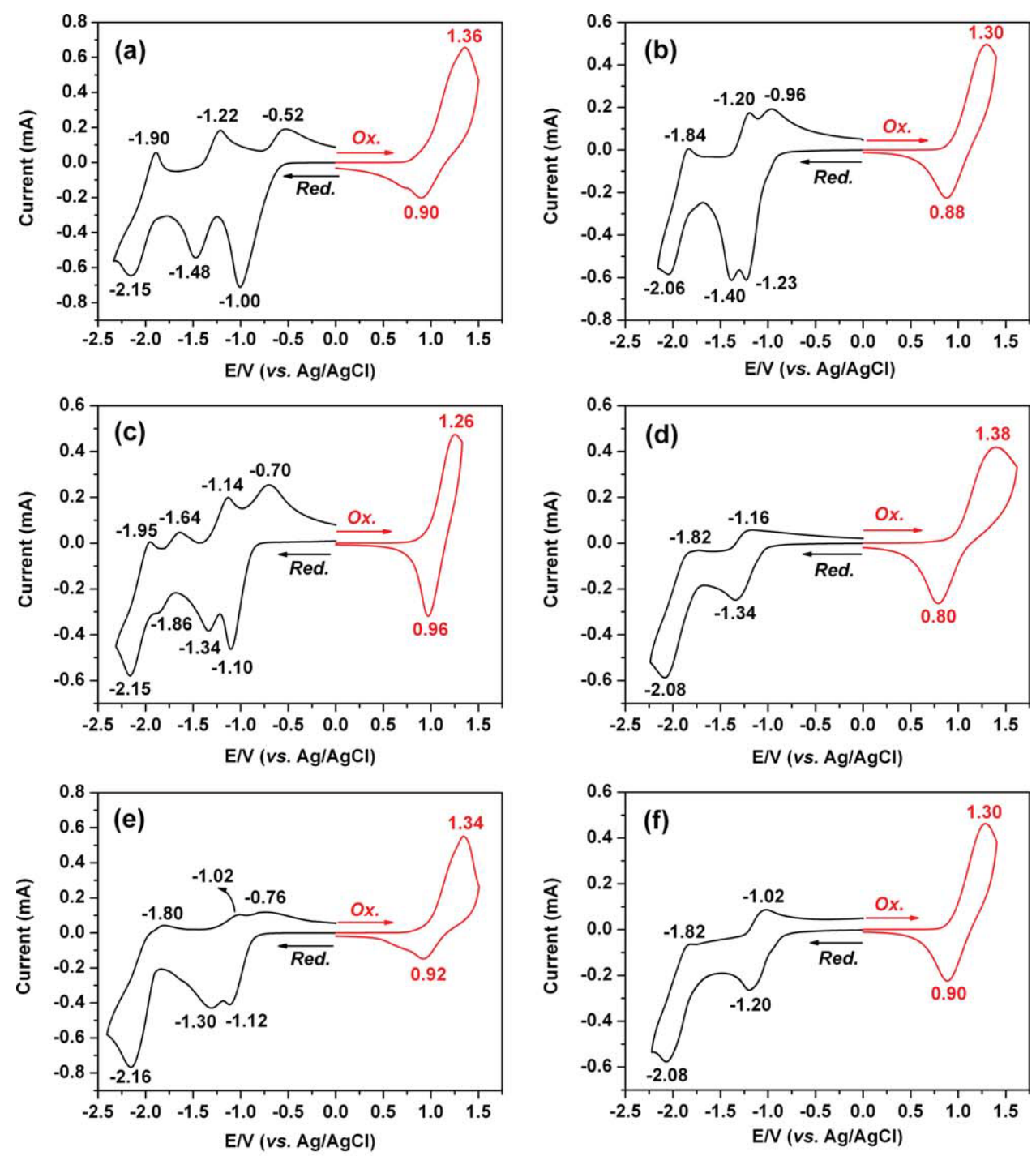

5 Cyclic voltammetric diagrams of the cast films of polyimides (a) $\mathbf{3 a}$, (b) $\mathbf{3 b}$, (c) $\mathbf{3 c}$, (d) 3d, (e) 3e, (f) 3f, (g) 3g, and (h) $3 \mathrm{~h}$ on an ITO-coated glass substrate in $0.1 \mathrm{M} \mathrm{Bu}_{4} \mathrm{NClO}_{4}$ acetonitrile (for anodic process) and DMF (for cathodic process) solution at a scan rate of 50 and 100 $\mathrm{mV} \mathrm{s}^{-1}$, respectively. [Color figure can be viewed in the online issue, which is available at wileyonlinelibrary.com.]
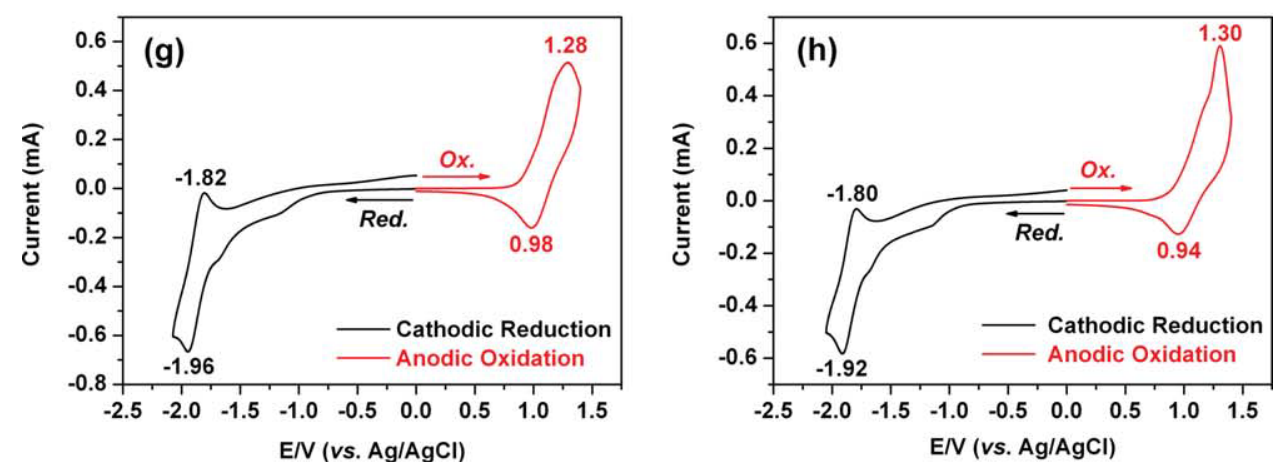

dianhydrides, only the reduction process of pyrene unit $\left(E_{\mathrm{pc}}\right.$ $=-1.96$ and $-1.92 \mathrm{~V}$, respectively) was observed [Figs. $5(\mathrm{~g}, \mathrm{~h})]$. The lack of imide reduction in these two polyimides should be a result of the reduced electron affinity due to the alicyclic structure. This result is similar to that observed for the model compound $\mathbf{M} 2$ as shown in Supporting Information Figure S5.

The energy levels of the highest occupied molecular orbital (HOMO) and lowest unoccupied molecular orbital (LUMO) of the corresponding polymers were estimated from the $E_{\mathrm{ox}}^{1 / 2}$ and first $E_{\text {red }}^{1 / 2}$ values. Assuming that the HOMO energy level for the ferrocene/ferrocenium $\left(\mathrm{Fc} / \mathrm{Fc}^{+}\right)$standard is $4.80 \mathrm{eV}$ with respect to the zero vacuum level, the HOMO and LUMO values for these polyimides were calculated to be in the range of $5.45-5.49 \mathrm{eV}$ and $2.48-3.61 \mathrm{eV}$, respectively.

\section{Spectroelectrochemical and Electrochromic Properties}

The electro-optical properties of the polymer films were investigated using the changes in electronic absorption 
TABLE 4 Redox Potentials and Energy Levels of Polyimides

\begin{tabular}{|c|c|c|c|c|c|c|c|c|c|c|}
\hline \multirow{3}{*}{$\begin{array}{l}\text { Polymer } \\
\text { Code }\end{array}$} & \multicolumn{2}{|c|}{ Oxidation Potential $(\mathrm{V})^{\mathrm{a}}$} & \multicolumn{5}{|c|}{ Reduction Potential $(\mathrm{V})^{\mathrm{b}}$} & \multirow[b]{3}{*}{$E_{\mathrm{g}}^{\mathrm{opt}}(\mathrm{eV})^{\mathrm{c}}$} & \multirow[b]{3}{*}{$E_{\mathrm{g}}^{\mathrm{ec}}(\mathrm{eV})^{\mathrm{d}}$} & \multirow{3}{*}{$\begin{array}{l}\text { HOMO/LUMO } \\
(\mathrm{eV})^{\mathrm{e}}\end{array}$} \\
\hline & \multirow[b]{2}{*}{$E_{\mathrm{ox}}^{\text {onset }}$} & \multirow[b]{2}{*}{$E_{\mathrm{ox}}^{1 / 2}$} & \multirow[b]{2}{*}{$E_{\text {red }}^{\text {onset }}$} & \multicolumn{4}{|c|}{$E_{\mathrm{red}}^{1 / 2}$} & & & \\
\hline & & & & $1 \mathrm{st}$ & 2nd & $3 r d$ & 4 th & & & \\
\hline $3 a$ & 0.95 & $1.13(1.17)^{f}$ & -0.65 & -0.75 & -1.35 & -2.00 & - & 2.67 & 1.88 & $5.49 / 3.61$ \\
\hline $3 \mathbf{b}$ & 0.95 & 1.09 (1.17) & -1.00 & -1.10 & -1.30 & -1.95 & - & 2.65 & 2.19 & $5.45 / 3.26$ \\
\hline $3 c$ & 0.97 & $1.11(1.17)$ & -0.88 & -0.90 & -1.24 & -1.75 & -2.05 & 2.68 & 2.01 & $5.47 / 3.46$ \\
\hline 3d & 0.97 & $1.09(1.14)$ & -1.06 & -1.25 & -1.95 & - & - & 2.71 & 2.34 & $5.45 / 3.11$ \\
\hline $3 e$ & 0.97 & $1.13(1.17)$ & -0.88 & -0.94 & -1.16 & -1.98 & - & 2.70 & 2.07 & $5.49 / 3.42$ \\
\hline $3 f$ & 0.92 & $1.10(1.18)$ & -0.92 & -1.11 & -1.95 & - & - & 2.70 & 2.21 & $5.46 / 3.25$ \\
\hline $3 g$ & 0.96 & $1.13(-)$ & -1.75 & -1.88 & - & - & - & 2.81 & 3.01 & $5.49 / 2.48$ \\
\hline $3 \mathrm{~h}$ & 0.94 & $1.12(-)$ & -1.72 & -1.86 & - & - & - & 2.82 & 2.98 & $5.48 / 2.50$ \\
\hline
\end{tabular}

a Verus $\mathrm{Ag} / \mathrm{AgCl}$ in $\mathrm{CH}_{3} \mathrm{CN}$. $E^{1 / 2}=$ average potential of the redox couple peaks.

b Versus $\mathrm{Ag} / \mathrm{AgCl}$ in DMF.

${ }^{c}$ Bandgaps calculated from absorption edge of the polymer films: $E_{g}^{o p t}$ $=1,240 / \lambda_{\text {onset }}$

${ }^{\mathrm{d}} E_{\mathrm{g}}^{\mathrm{ec}}$, electrochemical band gap is derived from the difference between HOMO and LUMO values. e The HOMO and LUMO energy levels were calculated from $E_{\text {ox }}^{1 / 2}$ and $E_{\text {red }}^{1 / 2}$ values of $\mathrm{CV}$ curves and were referenced to ferrocene (4.8 eV relative to the vacuum energy level).

${ }^{f}$ Values in parentheses are data of analogous polyimide $3^{\prime}$ having the corresponding $\mathrm{R}$ as that of the $\mathbf{3}$ series.

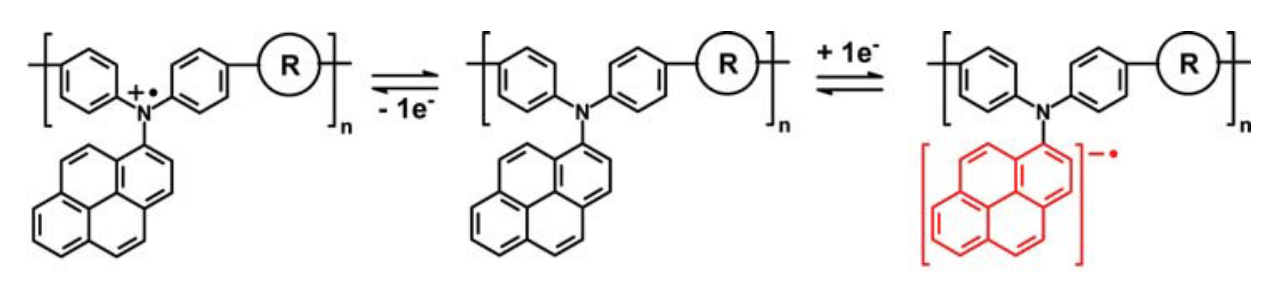

(R):
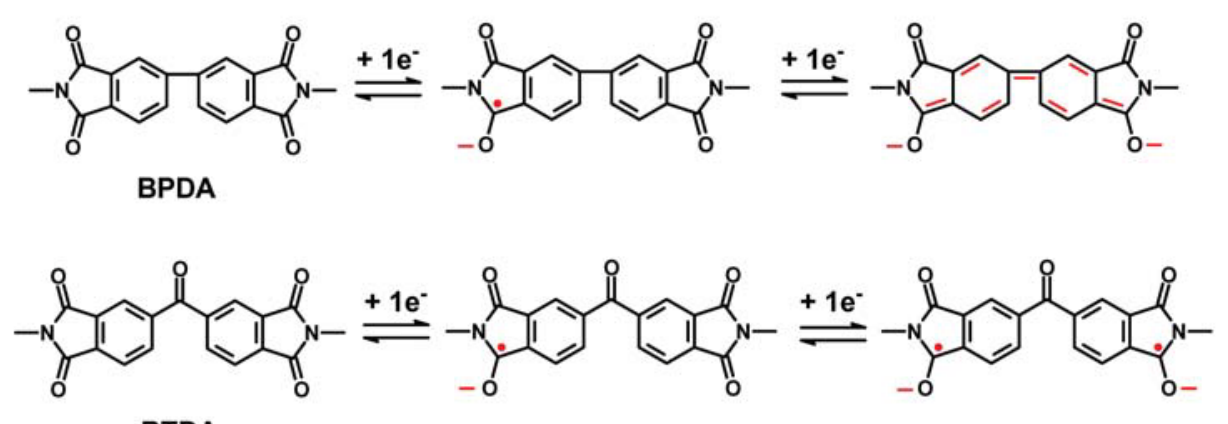

BTDA
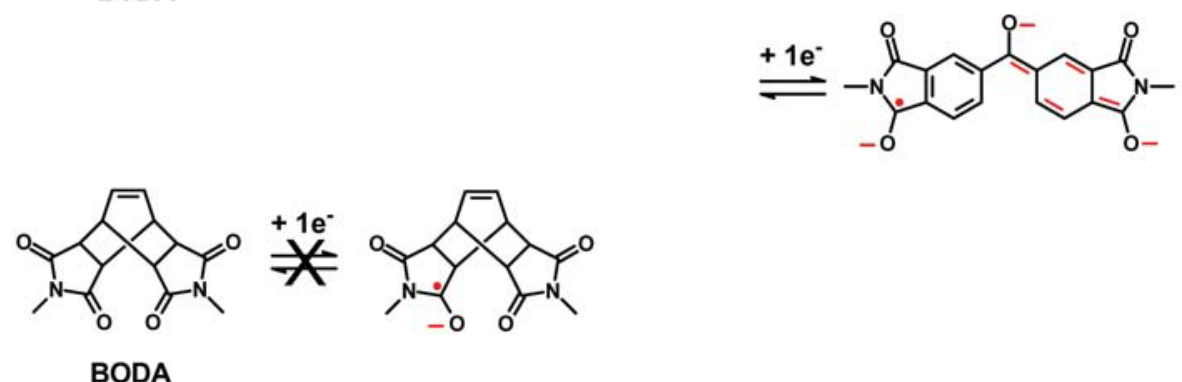

SCHEME 2 Postulated redox chemistry of pyrenylamine and some imide systems. [Color figure can be viewed in the online issue, which is available at wileyonlinelibrary.com.] 


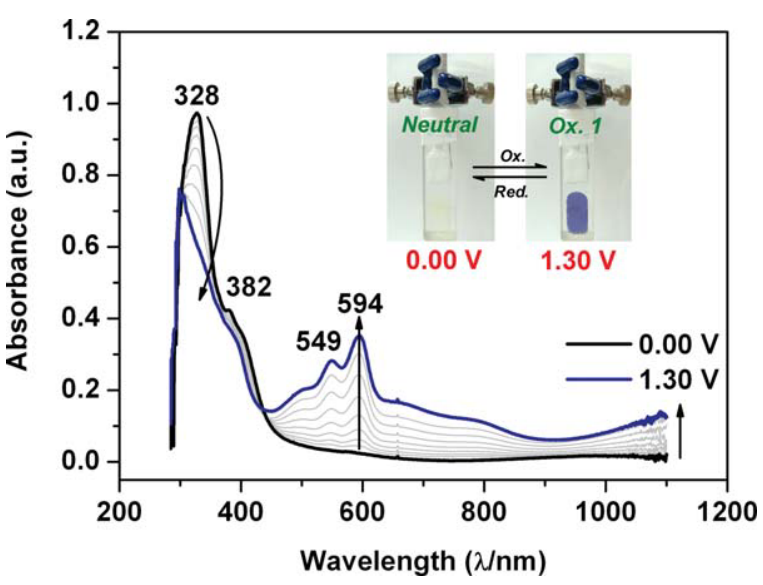

FIGURE 6 Electronic absorption change of $\mathbf{3 b}$ thin film on the ITO-coated glass substrate (in $\mathrm{CH}_{3} \mathrm{CN}$ with $0.1 \mathrm{M} \mathrm{Bu}_{4} \mathrm{NClO}_{4}$ as the supporting electrolyte) at various applied voltage potentials versus $\mathrm{Ag} / \mathrm{AgCl}$ The inset shows the $\mathrm{p}$-doping electrochromic photographic images of the film at indicated applied voltages. [Color figure can be viewed in the online issue, which is available at wileyonlinelibrary.com.]

spectra at various applied voltages. The result of the $\mathbf{3 b}$ film upon electro-oxidation (p-doping) is presented in Figure 6 as a series of UV-vis-NIR absorption curves correlated to electrode potentials. In the neutral form, the film exhibits a strong band at $328 \mathrm{~nm}$ with a shoulder at $382 \mathrm{~nm}$, but it is almost transparent at longer than $450 \mathrm{~nm}$. Upon oxidation of the $\mathbf{3 b}$ film (increasing electrode potential from 0 to $1.30 \mathrm{~V}$ ), the intensity of the absorption band at $328 \mathrm{~nm}$ gradually decreased, whereas new peaks at 549 and $594 \mathrm{~nm}$ in the visible region together with a broad band from $650 \mathrm{~nm}$ extending out into the NIR region beyond $1100 \mathrm{~nm}$ gradually increased in intensity. Meanwhile, the color of the film

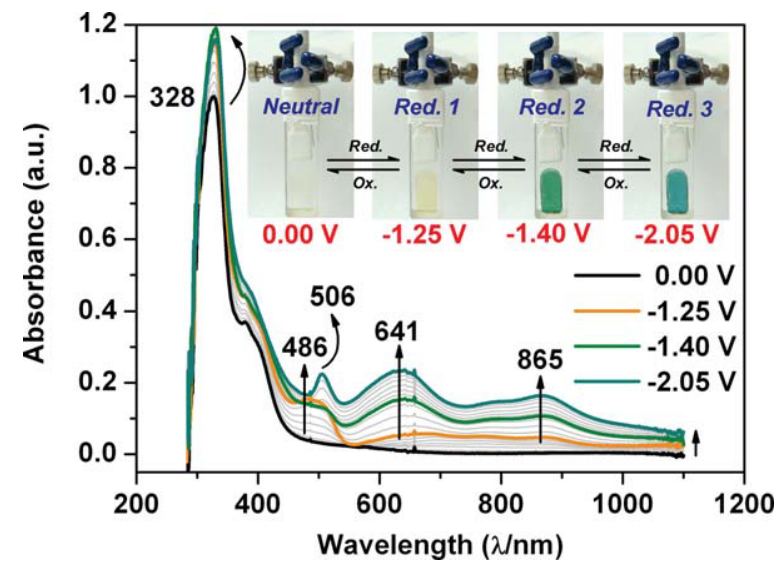

FIGURE 7 Electronic absorption change of $\mathbf{3 b}$ thin film on the ITO-coated glass substrate (in DMF with $0.1 \mathrm{M} \mathrm{Bu}_{4} \mathrm{NClO}_{4}$ as the supporting electrolyte) at various applied voltage potentials versus $\mathrm{Ag} / \mathrm{AgCl}$ The inset shows the $\mathrm{n}$-doping electrochromic photographic images of the film at indicated applied voltages. [Color figure can be viewed in the online issue, which is available at wileyonlinelibrary.com.] changed from pale yellow (near colorless) to purplish blue. We attribute these spectral changes to the formation of a stable radical cation of the diphenylpyrenylamine moiety. Figure 7 shows the spectral changes of the $\mathbf{3 b}$ film upon electro-reduction (n-doping). The radical anion of polyimide 3b, which appears at potentials between -1.00 and $-1.25 \mathrm{~V}$, exhibits a strong band at $328 \mathrm{~nm}$ and an increased absorption between 400 and $550 \mathrm{~nm}$. As shown in the inset of Figure 7 , the radical anion form of polyimide $\mathbf{3} \mathbf{b}$ is yellow in color. Further reduction at potentials negative to $-1.40 \mathrm{~V}$ results in the two-electron reduced (dianion) state with absorption maxima at 641 and $865 \mathrm{~nm}$, and the film turns to a green color during the second reduction. The spectrum
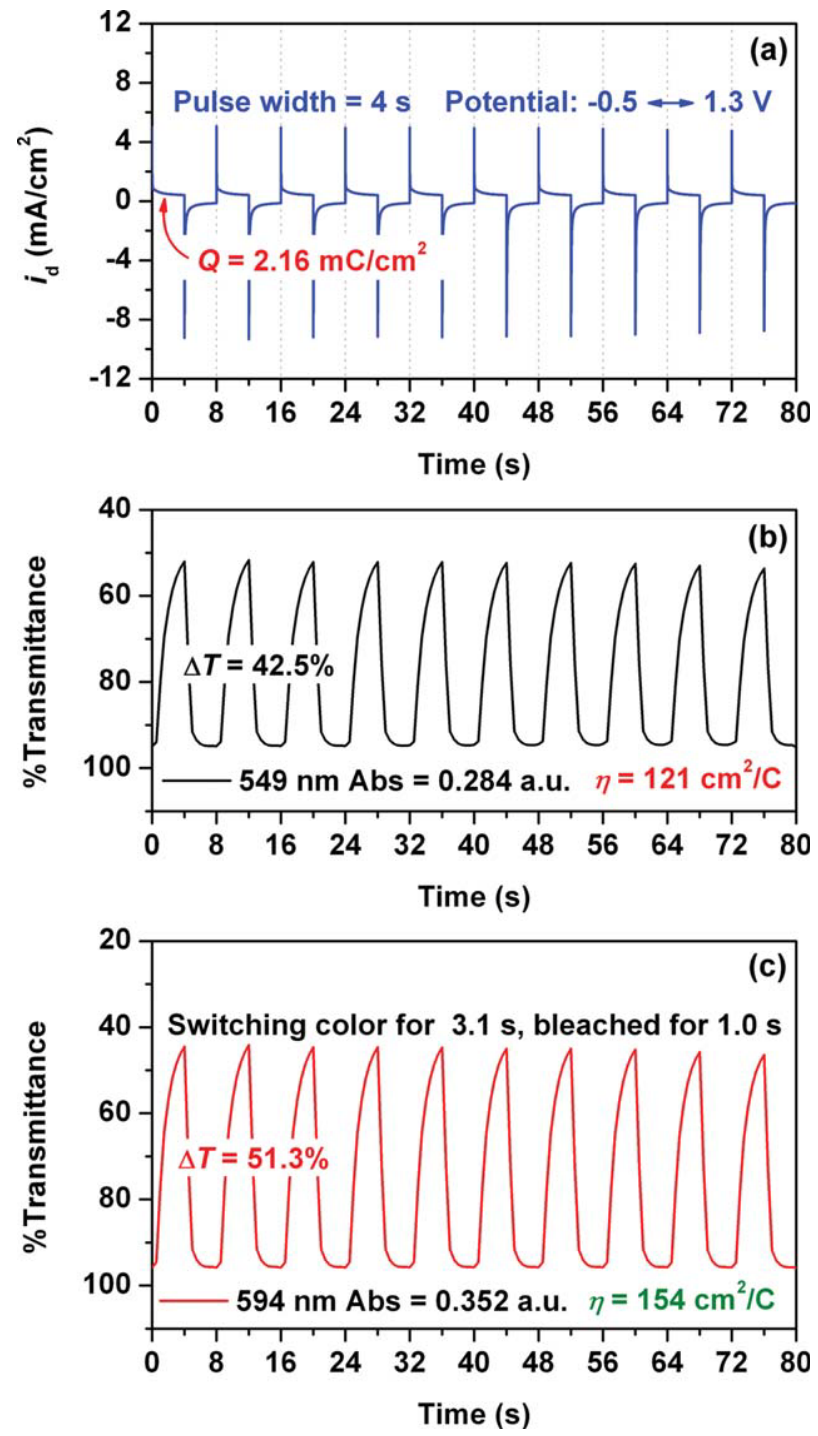

FIGURE 8 (a) Electrical current response, (b) transmittance change, and (c) as a function of time for the cast film of polyimide $\mathbf{3} \mathbf{b}$ on the ITO-coated glass slide (active area about 1 $\mathrm{cm}^{2}$ ) (in $0.1 \mathrm{M} \mathrm{Bu}_{4} \mathrm{NClO}_{4} / \mathrm{CH}_{3} \mathrm{CN}$ as the supporting electrolyte) by applying a potential step between -0.5 and $1.3 \mathrm{~V}$ (versus $\mathrm{Ag} / \mathrm{AgCl}$ ). [Color figure can be viewed in the online issue, which is available at wileyonlinelibrary.com.] 
at $-2.05 \mathrm{~V}$ has a new peak appearing at $506 \mathrm{~nm}$, together with further intensified absorptions around 641 and 865 $\mathrm{nm}$. As the potential examined is similar to the third cathodic process, the spectral change is assigned to the radical anion formation arising from the reduction of the pyrene unit. At this stage, the polymer film appears as a cyan color.

Electrochromic switching studies for the polyimides were performed to monitor the percent transmittance changes $(\Delta \% T)$ as a function of time at their absorption maximum $\left(\lambda_{\max }\right)$ and to determine the response time by stepping potential repeatedly between the neutral and oxidized states. The active area of the polymer film on ITO glass is about 1 $\mathrm{cm}^{2}$. Figure 8 depicts the optical transmittance as a function of time at 549 and $594 \mathrm{~nm}$ by applying squarewave potential steps of $4 \mathrm{~s}$ between -0.5 and $+1.30 \mathrm{~V}$. The response time was calculated at $90 \%$ of the full-transmittance change, because it is difficult to perceive any further color change with naked eye beyond this point. Polyimide $\mathbf{3 b}$ attained $90 \%$ of a complete coloring and bleaching in less than 4 and $1 \mathrm{~s}$, respectively. The optical contrast measured as $\Delta \% T$ of polyimide $\mathbf{3 b}$ between neutral pale yellow and oxidized purplish blue states was found to be $42.5 \%$ at $549 \mathrm{~nm}$ and $51.3 \%$ at $594 \mathrm{~nm}$. Coloration efficiency (CE; $\eta$ ) is a useful term for measuring the power efficiency of the electrochromic devices and can be calculated via optical density using the following equation: ${ }^{25,26}$

$$
\eta=\Delta \mathrm{OD}\left(\lambda_{\max }\right) / Q
$$

where $Q$ is the injected/extracted charge per unit electrode area $\left(\mathrm{mC} \mathrm{cm}^{-2}\right)$, and $\triangle O D$ is the change in absorbance at specific wavelength maximum during a redox step. The coloration efficiency of 3b film at 549 and $594 \mathrm{~nm}$ was calculated to be 121 and $154 \mathrm{~cm}^{2} \mathrm{C}^{-1}$, respectively, comparable to the reported data for some electrochromic $\pi$-conjugated polymers. ${ }^{27}$ The long-term stability of polyimide $\mathbf{3 b}$ was investigated by monitoring the electrochromic contrast $(\Delta \% T)$ of the thin film upon repeated squarewave potential steps of $4 \mathrm{~s}$ in a $0.1 \mathrm{M} \mathrm{Bu}_{4} \mathrm{~N}$ $\mathrm{ClO}_{4} / \mathrm{CH}_{3} \mathrm{CN}$ electrolyte solution between -0.5 and $+1.30 \mathrm{~V}$. In over 100 cycles under ambient conditions, polyimide $\mathbf{3 b}$ showed larger loss of electrochromic contrast (near 50\%) as compared to the polyamides (less than $5 \%$ ) derived from the same pyrenylamine-based diamine. ${ }^{18}$ These less stability might be attributable to the strong electron-withdrawing effect of the imide group. Even though the slightly lower long-term stability of polyimide $\mathbf{3 b}$, it still exhibited interesting ambipolar electrochromic behaviors upon oxidation or reduction.

\section{CONCLUSIONS}

A new series of electroactive polyimides incorporated with diphenylpyrenylamine group as a fluorophore and redoxchromophore have been synthesized. All the polymers could form morphologically stable and uniform amorphous films using solution-casting techniques. In addition to high $T_{\mathrm{g}}$, high thermal stability and strong fluorescence (for the semiaromatic polyimides), the polymers also revealed ambipolar multielectrochromic characteristics. Thus, these polyimides may find optoelectronic applications as new hole-transporting, light-emitting, and electrochromic materials.

The authors are grateful to the National Science Council in Taiwan (the Republic of China) for financial support of this work.

\section{REFERENCES AND NOTES}

1 (a) Polyimides; Wilson, D.; Stenzenberger, H. D.; Hergenrother, P. M., Eds.; Blackie: Glasgow and London, 1990; (b) Sroog, C. E. Prog Polym Sci 1991, 16, 561-694; (c) Polyimides: Fundamentals and Applications; Ghosh, M. K.; Mittal, K. L. Eds.; Marcel Dekker: New York, 1996.

2 For review papers: see (a) Huang, S. J.; Hoyt, A. E. TRIP 1995, 3, 262-271; (b) de Abajo, J.; de la Campa, J. G. Adv Polym Sci 1999, 140, 23-59; (c) Ding, M. Prog Polym Sci 2007, 32, 623-668; (d) Dhara, M. G.; Banerjee, S. Prog Polym Sci 2010, 35, 1022-1077.

3 For selected examples: see (a) Harris, F. W.; Hsu, S. L.-C. High Perform Polym 1989, 1, 3-16; (b) Matsuura, T.; Hasuda, Y.; Nishi, S.; Yamada, N. Macromolecules 1991, 24, 5001-5005; (c) Wang, Z. Y.; Qi, Y. Macromolecules 1995, 28, 4207-4212; (d) Chung, I. S.; Kim, S. Y. Macromolecules 2000, 33, 3190-3193; (e) Zhang, H. B.; Wang, Z. Y. Macromolecules 2000, 33, 4310-4312; (f) Chou, C.-H.; Reddy, D. S.; Shu, C.-F. J Polym Sci Part A: Polym Chem 2002, 40, 3615-3621; (g) Hsiao, S.-H.; Lin, K.-H. J Polym Sci Part A: Polym Chem 2005, 43, 331-341; (h) Kwak, S. M.; Yeon, J. H.; Yoon, T. H. J Polym Sci Part A: Polym Chem 2006, 44, 2567-2578; (i) Chern, Y.-T.; Tsai, J.-Y.; Wang, J.-J. J Polym Sci Part A: Polym Chem 2009, 47, 2443-2452; (j) Chung, C. W.; Lin, C. H.; Cheng, P. W.; Hwang, H. J.; Dai, S. A. J Polym Sci Part A: Polym Chem 2009, 47, 2486-2499; (k) Zhang, S. J.; Li, Y. F.; Ma, T.; Zhao, J. J.; Xu, X. Y.; Yang, F. C.; Xiang, X. Y. Polym Chem 2010, 1, 485-493; (I) Liu, Y.; Xing, Y.; Zhang, Y. H.; Guan, S. W.; Zhang, H. B.; Wang, Y.; Wang, Y. P.; Jiang, Z. H. J Polym Sci Part A: Polym Chem 2010, 48, 3281-3289; (m) Calle, M.; Lozano, A. E.; de la Campa, J. G.; de Abajo, J. Macromolecules 2010, 43, 2268-2275.

4 Winnik, F. M. Chem Rev 1993, 93, 587-614.

5 Selected references: (a) Zhou, W. D.; Li, Y. J.; Li, Y. L.; Liu, H. B.; Wang, S.; Li, C. H.; Yuan, M. J.; Liu, X. F.; Zhu, D. B. Chem Asian J 2006, 1-2, 224-230; (b) Choi, J. K.; Kim, S. H.; Yoon, J.; Lee, K.-H.; Bartsch, R. A.; Kim, J. S. J Org Chem 2006, 71, 8011-8015; (c) Colquhoun, H. M.; Zhu, Z. X.; Cardin, C. J.; Gan, Y.; Drew, M. G. B. J Am Chem Soc 2007, 129, 16163-16174; (d) Conlon, P.; Yang, C. J.; Wu, Y. R.; Chen, Y.; Martinez, K.; Kim, Y.; Stevens, N.; Marti, A. A.; Jockusch, S.; Turro, N. J.; Tan, W. H. J Am Chem Soc 2008, 130, 336-342; (e) Ivan, M. G.; Scalano, J. C. Chem Mater 2009, 21, 3933-3940; (f) Gao, Y. W.; Bai, H.; Shi, G. Q. J Mater Chem 2010, 20, 2993-2998.

6 (a) Liu, F.; Tang, C.; Chen, Q.-Q.; Shi, F.-F.; Wu, H.-B.; Xie, L.H.; Peng, B.; Wei, W.; Cao, Y.; Huang, W. J Phys Chem C 2009, 113, 4641-4647; (b) Wee, K.-R.; Ahn, H.-C.; Son, H.-J.; Han, W.-S.; Kim, J.-E.; Cho, A. W.; Kang, S. O. J Org Chem 2009, 74, 8472-8475; (c) Lai, S.-L.; Tong, Q.-X.; Chan, M.-Y.; Ng, T.-W.; Lo, M.-F.; Lee, S.-T.; Lee, C.-S. J Mater Chem 2011, 21, 1206-1211.

7 (a) Kawano, S.-I.; Yang, C. D.; Ribas, M.; Baluschev, S.; Baumgarten, M.; Mullen, K. Macromolecules 2008, 41, 
7933-7937; (b) Figueira-Duarte, T. M.; del Rosso, P. G.; Trattnig, R.; Sax, S.; List. E. J. W.; Mullen, K. Adv Mater 2010, 22, 990-993; (c) Chen, H.; Hu, X.; Ng, S.-C. J Polym Sci Part A: Polym Chem 2010, 48, 5562-5569.

8 (a) Xia, R. D.; Lai, W.-Y.; Levermore, P. A.; Huang, W.; Bradley, D. D. Adv Funct Mater 2009, 19, 2844-2850; (b) Liu, F.; Zou, J.-H.; He, Q.-Y.; Tang, C.; Xie, L.-H.; Peng, B.; Wei, W.; Huang, W. J Polym Sci Part A: Polym Chem 2010, 48, 4943-4949.

9 (a) Sudhakar, S.; Sellinger, A. Macromol Rapid Commun 2006, 27, 247-254; (b) Bernhardt, S.; Kastler, M.; Enkelmann, V.; Baumgarten, M.; Mullen, K. Chem Eur J 2006, 12, 6117-6128; (c) Figueira-Duarte, T. M.; Simon, S. C.; Wagner, M.; Druzhinin, S. I.; Zachariasse, K. A.; Mullen, K. Angew Chem Int Ed 2008, 47, 10175-10178; (d) Gingras, M.; Placide, V.; Raimundo, J.-M.; Bergamini, G.; Ceroni, P.; Balzani, V. Chem Eur J 2008, 14, 10357-10363.

10 Moorthy, J. N.; Natarajan, P.; Venkatakrishnan, P.; Huang, D.-F.; Chow, T.-J. Org Lett 2007, 9, 5215-5218.

11 (a) Shen, J. Y.; Lee, C. Y.; Huang, T.-H.; Lin, J. T.; Tao, Y.T.; Chien, C.-H.; Tsai, C. T. J Mater Chem 2005, 15, 2455-2463; (b) Huang, T.-H.; Whang, W.-T.; Shen, J. Y.; Lin, J. T.; Zheng, H. J Mater Chem 2005, 15, 3233-3240; (c) Thomas, K. R. J.; Velusamy, M.; Lin, J. T.; Chuen, C. H.; Tao, Y.-T. J Mater Chem 2005, 15, 4453-4459; (d) Pu, Y.-J.; Higashidate, M.; Nakayama, K.; Kido, J. J Mater Chem 2008, 18, 4183-4188.

12 (a) Selby, T. D.; Blackstock, S. C. J Am Chem Soc 1999, 121, 7152-7153; (b) Selby, T. D.; Kim, K.-Y.; Blackstock, S. C. Chem Mater 2002, 14, 1685-1690; (c) Ito, A.; Ino, H.; Tanaka, K.; Kanemoto, K.; Kato, T. J Org Chem 2002, 67, 491-498; (d) Fukuzaki, E.; Nishide, H. Org Lett 2006, 8, 1835-1838.

13 (a) Shirota, Y. J Mater Chem 2000, 10, 1-25; (b) Shirota, Y. J Mater Chem 2005, 15, 75-93; (c) Shirota, Y.; Kageyama, H. Chem Rev 2007, 107, 953-1010.

14 Thelakkat, M. Macromol Mater Eng 2002, 287, 442-461.

15 Tang, C. W.; VanSlyke, S. A. Appl Phys Lett 1987, 51, 913-915.

16 (a) Cheng, S.-H.; Hsiao, S.-H.; Su, T.-H.; Liou, G.-S. Macromolecules 2005, 38, 307-316; (b) Hsiao, S.-H.; Chang, Y.-M.; Chen, H.-W.; Liou, G.-S. J Polym Sci Part A: Polym Chem 2006,
44, 4579-4592; (c) Liou, G.-S.; Hsiao, S.-H.; Chen, H.-W. J Mater Chem 2006, 16, 1831-1842; (d) Chang, C.-W.; Liou, G.-S.; Hsiao, S.-H. J Mater Chem 2007, 17, 1007-1015; (e) Wang, H.-M.; Hsiao, S.-H. Polymer 2009, 50, 1692-1699; (f) Hsiao, S.-H.; Liou, G.-S.; Kung, Y.-C.; Pan, H.-Y.; Kuo, C.-H. Eur Polym J 2009, 45, 2234-2248.

17 (a) Hsiao, S.-H.; Liou, G.-S.; Kung, Y.-C.; Yen, H.-J. Macromolecules 2008, 41, 2800-2808; (b) Kung, Y.-C.; Liou, G.-S.; Hsiao, S.-H. J Polym Sci Part A: Polym Chem 2009, 47, 1740-1755; (c) Hsiao, S.-H.; Liou, G.-S.; Wang, H.-M. J Polym Sci Part A: Polym Chem 2009, 47, 2330-2343; (d) Hsiao, S.-H.; Liou, G.-S.; Kung, Y.-C.; Chang, Y.-M. J Polym Sci Part A: Polym Chem 2010, 48, 2798-2809; (e) Hsiao, S.-H.; Liou, G.-S.; Kung, Y.-C.; Hsiung, T.-J. J Polym Sci Part A: Polym Chem 2010, 48, 3392-3401; (f) Wang, H.-M.; Hsiao, S.-H.; Liou, G.-S.; Sun, C.-H. J Polym Sci Part A: Polym Chem 2010, 48, 4775-4789; (g) Wang, H.-M.; Hsiao, S.-H. J Polym Sci Part A: Polym Chem 2011, 49, 337-351.

18 Kung, Y.-C.; Hsiao, S.-H. J Mater Chem 2010, 20, 5481-5492.

19 Kung, Y.-C.; Hsiao, S.-H. J Mater Chem 2011, 21, 1746-1754.

20 Oishi, Y.; Takado, H.; Yoneyama, M.; Kakimoto, M.; Imai, Y. J Polym Sci Part A: Polym Chem 1990, 28, 1763-1769.

21 Demas, J. N.; Crosby, G. A. J Phys Chem 1971, 75, 991-1024.

22 (a) Kalyanasundaram, K.; Thomas, J. K. J Am Chem Soc 1977, 99, 2039-2044; (b) Karpovich, D. S.; Blanchard, G. J. J Phys Chem 1995, 99, 3951-3958.

23 Mazur, S.; Lugg, P. S.; Yarnitzky, C. J Electrochem Soc 1987, 134, 346-353.

24 Viehbeck, A.; Goldberg, M. J.; Kovac, C. A. J Electrochem Soc 1990, 137, 1460-1466.

25 Monk, P. M. S.; Mortimer, R. J.; Rosseinsky, D. R. Electrochromism and Electrochromic Devices; Cambridge University Press: Cambridge, UK, 2007.

26 Beaujuge, P. M.; Reynolds, J. R. Chem Rev 2010, 110, 268-320.

27 (a) Cihaner, A.; Algi, F. Electrochim Acta 2008, 54, 665-670; (b) Cihaner, A.; Algi, F. Adv Funct Mater 2008, 18, 3583-3589. 